\title{
A Factor Analysis on the Financial Industry Agglomeration of Beijing
}

\author{
Pengyuan $\mathrm{Xu}^{1, \mathrm{a}}$, Meiqing Zhang ${ }^{1, \mathrm{~b}}$
}

${ }^{1}$ School of Economics and Management, Beijing Jiaotong University, Haidian District, Beijing, China

\author{
a14120527@bjtu.edu.cn, bmeiqing_zhang@sina.com
}

Key words: Financial Industry Agglomeration, Factor Analysis, Common Factors

Abstract: This paper describes the characteristics of financial industry clusters of Beijing and discuss the factors affecting those, using factor analysis to extract common factors from the hypothetical indicators that may affect the financial industry gathering. Research shows that Beijing's financial industry has a high local degree of specialization, and its degree of agglomeration shows a strong positive correlation with the "modernization factor" on behalf of indicators representing the degree of modernization of Beijing's per capita income, level of information and economic system, and "human capital factor" representing Beijing's human capital.

\section{Introduction}

Beijing is not only China's political, cultural, scientific, educational and international exchange center, but also an international metropolis. Beijing's financial industry has also made great progress, as of early 2013, the scale of financial assets amounted to 49.5 trillion yuan, accounting for 78.4 percent of Beijing and $52 \%$ of the country ${ }^{1}$

Beijing's economy cannot obtain a higher level of coordination of development in a broader field without the agglomeration of financial sector. Meanwhile, the economic development at home and abroad shows that spatial concentration has become a trend in the development of the financial industry, which is becoming the backbone of regional economic competitiveness.

The financial sector has a profound significance and impact on regional economic development through the economies of scale, economies of scope, agglomeration benefits and radiation effects, etc. The financial sector is a result of the evolution of financial industry gathering, which may form a financial center. The financial sector can enhance the overall competitiveness of the financial sector to contribute to regional economic development. So in this context we must consider the following questions: What is the status of Beijing Financial Industry agglomeration, and what is the influence factors of Beijing's financial industry agglomeration? Currently in Beijing how to promote the gathering level of financial sector? What follows in the passage will present the status of the financial industry agglomeration in Beijing and analyze the factors influencing agglomeration using factor analysis.

\section{Characteristics of Beijing Financial Industry Cluster}

The measurement of industrial agglomeration has different calculation methods based on different perspectives. As is apparent from the business point of view, it can be measured by the Herfindahl index. From the industry perspective, the space can be measured by the Gini coefficient.

H.I Index. H.I index is the comprehensive index of market concentration, also known as Hirschman - Herfindahl index, the formula is:

$$
\text { H. I }=\sum_{j=i}^{N} S_{j}^{2}=\sum_{j=1}^{N}\left(X_{j} / X\right)^{2} .
$$

$X_{j}$ is the number of representatives of industrial enterprises' production, sales, assets or employees, corresponding to the total amount of $\mathrm{X}$ on behalf of industry data. $S_{j}=X_{j} / X$ are representative of the $\mathrm{i}$-th company's market share, $\mathrm{n}$ indicates the number of companies within the

1 The data is from "Beijing Statistical Yearbook" 
industry. Calculation results are shown below:

Table1. 2004--2013 major service industry in Beijing H.I index

\begin{tabular}{|c|c|c|c|c|}
\hline Year & Real estate & $\begin{array}{l}\text { Wholesale and } \\
\text { retail }\end{array}$ & IT & Finance \\
\hline 2004 & 0.03024 & 0.04040 & 0.00396 & 0.12875 \\
\hline 2005 & 0.00165 & 0.04232 & 0.00384 & 0.19499 \\
\hline 2006 & 0.01622 & 0.02117 & 0.00246 & 0.12483 \\
\hline 2007 & 0.01549 & 0.03042 & 0.00190 & 0.21926 \\
\hline 2008 & 0.04349 & 0.04055 & 0.00248 & 0.26086 \\
\hline 2009 & 0.05932 & 0.03717 & 0.00221 & 0.28168 \\
\hline 2010 & 0.02020 & 0.01867 & 0.00226 & 0.20561 \\
\hline 2011 & 0.03740 & 0.01452 & 0.00240 & 0.19729 \\
\hline 2012 & 0.04247 & 0.02151 & 0.00236 & 0.21952 \\
\hline 2013 & 0.08052 & 0.02210 & 0.00272 & 0.20037 \\
\hline Average & 0.03470 & 0.02888 & 0.00266 & 0.20332 \\
\hline
\end{tabular}

Source: "Beijing Statistical Yearbook 2005-2014". The data is from six central districts of Beijing, Haidian District, Xicheng District, Dongcheng District, Chaoyang District, Fengtai District and Shijingshan District.

From the average results, HI index has sorted the industries, financial sector $>$ Real Estate $>$ wholesale and retail trade $>$ renting and business services $>$ IT industry, since the closer and business a few more, HI index is closer to zero with more similar intra-industry enterprise size and larger quantity of firms, so the degree of agglomeration of each industry is the financial sector> Real Estate $>$ wholesale and retail trade $>$ renting and business services $>$ IT industry. So we can see a high level of Beijing Financial Industry Cluster.

EG Index. Agglomeration Index (EG index) is created by Ellison and Glaeser in order to solve spatial distortion of Gini coefficient, the extent to measure industry agglomeration. Assuming that an industry within an economy with $\mathrm{N}$ economy enterprises divided into $\mathrm{M}$ geographical regions. The formula is:

$$
\beta=\sum_{i=1}^{M}\left(p_{i}-q_{i}\right)^{2}-\left(1-\sum_{i=1}^{M} q_{i}^{2}\right) \sum_{j=i}^{N} S_{j}^{2} /\left(1-\sum_{i=1}^{M} q_{i}^{2}\right)\left(1-\sum_{j=i}^{N} S_{j}^{2}\right) .
$$

Where $\beta$ represents industry agglomeration index, $p_{i}$ is the regional employment proportion of the total employment in the industry of six districts of Beijing, $q_{i}$ is the regional employment proportion of the total employment in the city of Beijing. $S_{j}$ is the company's market share, using H.I index H.I $=\sum_{j=i}^{N} S_{j}^{2}=\sum_{j=1}^{N}\left(X_{j} / X\right)^{2}$.

Table2. 2004--2013 EG index of Beijing Financial Industry

\begin{tabular}{cc}
\hline$[$ year $]$ & {$[$ EG index $]$} \\
\hline$[2004]$ & {$[0.0256]$} \\
{$[2005]$} & {$[0.0363]$} \\
{$[2006]$} & {$[0.0672]$} \\
{$[2007]$} & {$[0.0003]$} \\
{$[2008]$} & {$[0.0025]$} \\
{$[2009]$} & {$[0.2234]$} \\
{$[2010]$} & {$[0.2770]$} \\
{$[2011]$} & {$[0.2311]$} \\
{$[2012]$} & {$[0.1862]$} \\
{$[2013]$} & {$[0.1494]$} \\
\hline
\end{tabular}

Source: Beijing Statistical Yearbook 2005-2014, "Beijing Regional Statistical Yearbook", CSMAR database.

Ellison and Glaeser divided the spatial concentration index into three intervals, the first interval, $\beta<0.02$, indicating that the industry has not localized, a low degree of agglomeration industry; secondary interval, $0.02 \leq \beta \leq 0.05$, showing that the distribution of industries in the region is more uniform, which is called moderate agglomeration. The third interval, $0.05<\beta$, indicating that the industry's highest degree of concentration in the area, known as highly concentrated industry. The value of the EG index of financial industry in Beijing is greater than 0.05 , belonging to the 
highly concentrated industry.

\section{Hypothesis about the Factors of Financial Agglomeration}

Population and Urban Scale Factor. Urban economists believe urban scale expansion of the city in each industry will generate positive externalities. From the labor market, the expansion of the city provides space for labor transactions between industries, effectively reducing the search costs for labor. At the same time expanding the size of the cities means more jobs! Better living conditions and more extensive cultural and recreational activities. These will attract a lot of people with different backgrounds to move into the city. From the industrial point of view, urban expansion is accompanied by the improvement of urbanization, improving inner-city urbanization to cause significant changes in the industrial structure! With urbanization at different stages of development, manufacturing and service industries alternately become the city's leading industry in the early stage of urban development. The manufacturing sector is the main driving force of urbanization, but with further improvement of the level of urbanization, urbanization of major substantive content will transfer to service industry. The service sector is gradually gathering in the city. Therefore, we assume that population size and city size have an impact on the financial industry gathering.

External Economic. External economic refers to the mutual effects in space between the second and tertiary industries, or among business units adjacent to each other, resulting lower costs and higher economic profits. External economic performs through the establishment and development of an enterprise to reduce the operating costs of other businesses or increase the competitiveness, including physical spillover and intellectual spillover. Among them, intellectual spillover refers to research and have a positive impact on the surrounding businesses, such as China's Zhongguancun, the Silicon Valley of the United States. Glaser and Ellison believes external economic effects is the second industrial concentration power. Where human capital plays an important role in its external economic effects, whereas the spillover of knowledge is the concrete manifestation of this effect.

Transaction Costs. Coase uses the transaction cost theory to explain the industry gathering. He believes that the number of industrial clusters of many enterprises reduce the transaction cost to increase trading frequency stability of objects. The smaller spatial distance between similar businesses improve symmetry of the information and suppress the acts of financial opportunism, saving search time of market information and reduce the cost.

Institutional Environment. Institutional environment has a profound impact on the development of an industry. This paper attempts to examine the formal impact on the industrial agglomeration from the formal system, which manifests the regulatory measures from local government sector to industrial sectors, mainly referring to regional protectionism. Almost all of the local governments, both in developed and developing countries have the motivation of local protectionism, which is dependent on the local taxes and employment levels. For the sake of political foundation and private interests, local Government is motivated to enterprises in the areas. Therefore, this article will examine this factor.

\section{Empirical Analysis}

Extract common factors. Combining with the previous proposed hypothesis of this paper, the following data were collected as nine variables which are analyzed using common factor analysis, as is shown below. 
Table3 Variables and Meanings

\begin{tabular}{|c|c|c|}
\hline Variables & [Meaning] & [Hypothetical related factors] \\
\hline [Var3] & [Teledensity (Including mobile phones) (/ 100 persons )] & {$[(2)$ (3) $]$} \\
\hline [Var4] & $\begin{array}{l}\text { [Public transport vehicles accounting for the proportion } \\
\text { of total motor vehicle] }\end{array}$ & [(2)] \\
\hline [Var5] & $\left[\right.$ Urban density (persons $\left.\left./ \mathrm{km}^{2}\right)\right]$ & [(1)(2) (3) \\
\hline [Var6] & [GDP per capita (10 thousand yuan)] & [(1)(3) (4)] \\
\hline [Var7] & $\begin{array}{l}\text { [full-time teachers in universities per } 10 \text { thousand } \\
\text { people] }\end{array}$ & [(2)] \\
\hline [Var8] & $\begin{array}{l}\text { [Employment of state-owned enterprises in total } \\
\text { employment share[ }\end{array}$ & [(2)] \\
\hline [Var9] & $\begin{array}{l}\text { [Private economy (excluding individual economic) } \\
\text { proportion of employees in total employment] }\end{array}$ & [(2)] \\
\hline [Var10] & [Fiscal expenditure share of GDP] & [(4) (1) (2)] \\
\hline [Var11] & $\begin{array}{l}\text { [Full-time teachers of adult vocational education per } 10 \\
\text { thousand people] }\end{array}$ & [(2)] \\
\hline
\end{tabular}

Note: The values are the ratio of the variables to the total of the country. (1) represents the factor of Population and Urban Scale Factor; (2)represents external economics; (3)represents Transaction Costs; (4)is the Institutional Environment

We use stata to give the main component factors, as is shown below.

\begin{tabular}{c|rrrr}
\hline Factor & Eigenvalue & Difference & Proportion & Cumulative \\
\hline Factor1 & 6.75225 & 5.50688 & 0.7823 & 0.7823 \\
Factor2 & 1.24537 & 0.88008 & 0.1443 & 0.9266 \\
Factor3 & 0.36529 & 0.19326 & 0.0423 & 0.9690 \\
Factor4 & 0.17203 & 0.06337 & 0.0199 & 0.9889 \\
Factor5 & 0.10866 & 0.10327 & 0.0126 & 1.0015 \\
Factor6 & 0.00539 & 0.00646 & 0.0006 & 1.0021 \\
Factor7 & -0.00107 & 0.00147 & -0.0001 & 1.0020 \\
Factor8 & -0.00253 & 0.01198 & -0.0003 & 1.0017 \\
Factor9 & -0.01452 &. & -0.0017 & 1.0000 \\
\hline
\end{tabular}

Figure 1. Cumulative Variance and Factor Scores before Extracting Common Factor

According to the above figure, stata default gives six common factors, but the cumulative variance contribution rate of the second factor reached $92.66 \%$, and the first factor can explain $78.23 \%$ of the variance of the original variables. Only the first two common factors with eigenvalues are greater than 1, so we need further examine the common factors.

Continuing the above steps, we obtain analytical results in the table below after the extraction of two common factors (Fig.2).

Factor loadings (pattern matrix) and unique variances

\begin{tabular}{r|rr|r}
\hline Variab1e & Factor1 & Factor2 & Uniqueness \\
\hline var3 & 0.9844 & -0.0494 & 0.0285 \\
$\operatorname{var} 4$ & 0.8678 & 0.0285 & 0.2460 \\
$\operatorname{var} 5$ & 0.7974 & -0.3437 & 0.2460 \\
$\operatorname{var} 6$ & 0.8939 & 0.4056 & 0.0365 \\
$\operatorname{var} 7$ & 0.9847 & 0.0598 & 0.0267 \\
$\operatorname{var} 9$ & 0.9222 & 0.3035 & 0.0575 \\
$\operatorname{var} 10$ & 0.9026 & -0.1825 & 0.1520 \\
$\operatorname{var} 11$ & -0.8974 & -0.1302 & 0.1778 \\
$\operatorname{var} 12$ & -0.3940 & 0.9020 & 0.0312 \\
\hline
\end{tabular}

Figure 2.Cumulative Variance and Factor Scores after Extracting Common Factor

Next, we use orthogonal rotation transformation to simplify the factor structure. We get factor loading matrix. We combine these results to sort out orthogonal factor table (Tab.4). 
Table 4. Orthogonal Factors

\begin{tabular}{|c|c|c|}
\hline \multirow{2}{*}{ [variables] $\quad$ [factors $]$} & [Factor] & [Factor] \\
\hline & [1] & [2] \\
\hline [Var3 & {$[0.8975]$} & {$[0.4073]$} \\
\hline [Var4] & [0.8177] & {$[0.2920]$} \\
\hline [Var5] & [0.6156] & [0.6124] \\
\hline [Var6] & {$[0.9804]$} & {$[-0.0491]$} \\
\hline [Var7] & {$[0.9379]$} & [0.3059] \\
\hline [Var8] & {$[0.9692]$} & [0.0562] \\
\hline [Var9] & {$[0.7726]$} & [0.5011] \\
\hline [Var10] & {$[-0.8825]$} & {$[-0.2083]$} \\
\hline [Var11] & {$[-0.0354]$} & {$[-0.9836]$} \\
\hline
\end{tabular}

According to the table we divide two categories of variable with high loadings (Tab.5), which have different corresponding relations compared to the hypothesis.

Table 5. Categories

\begin{tabular}{ccc}
\hline & [Variables with High Loading] & [Name] \\
\hline$[1]$ & [Var3 Var4 Var6 Var7 Var8 & [Modernization factor] \\
Var9 Var10] & {$[$ [Var11] } & [Human capital factor] \\
\hline
\end{tabular}

Followed by a subsequent drawing command we use loading plot factor analysis to visualize it. From the figure we can directly see the common factor 1, which we rename it Modernization factor, is related with Var1 Var2, Var4, Var5, Var6, Var7, Var8. These seven variable values are close to 1 or -1 . As for the common factor 2, the value of Var12 is close to -1 , which we rename it Human capital factor.

\section{Regression Analysis}

We measure the degree of concentration of the financial industry in Beijing with EG Index $\beta$.

Table 6. Output of Regression

\begin{tabular}{cc}
\hline \multicolumn{2}{c}{ [Dependent variable: local specialization index $\beta]$} \\
\hline [Independent variable:EG Idex $\beta]$ \\
\hline [Constant] & {$[2.179836]$} \\
{$\left[\mathrm{X} \_1\right.$ (Modernization factor) $]$} & $(2.000494)$ \\
& {$[.1698025]$} \\
{$\left[\mathrm{X} \_2\right.$ (Human capital factor) $]$} & .05225 \\
{$[\mathrm{~N}]$} & {$[922.2374]$} \\
{$\left[\mathrm{R}^{2}\right]$} & $(204.4872)$ \\
\hline
\end{tabular}

Note: The data in the parentheses is the standard error of the coefficient

As can be seen from the table, use this article extracted "modernization factor" and "human capital factor" in Beijing where the financial industry specialization after the regression analysis extracted "modernization factor" and "human capital factor" in Beijing, the results obtained are significant, which also confirms the hypothesis from the third part of this paper.

\section{Conclusions}

This article is based on the new economic geography. By summarizing the results of previous studies and the actual development of the financial sector in Beijing, this paper puts forward the hypothesis of the factors that may have effects on the agglomeration of Beijing's financial industry. We use common factor analysis to extract factors from these variables, followed by the regression of factors on the EG Index of Beijing, and finally reach the following conclusions.

First, the urban per capita income is one of the main factors influencing the city's development of finance. Combining Beijing's ten years data, the correlation coefficient between factors $\mathrm{x} 1$ and Beijing is close to 1 per capita GDP, fully illustrating this point.

Second, the degree of informatization will affect the transaction costs of the financial industry in 
Beijing, and then affect the development of Beijing's financial industry.

Third, the external economic effects of knowledge spillovers affect the quality of human capital in Beijing financial industry, has a strong positive correlation with the degree of financial industry agglomeration in Beijing.

\section{Summary}

The economic development of Beijing depends on the agglomeration of Beijing' financial industry for the reason that the output of financial industry accounts for a large part of Beijing's GDP. This paper describes the characteristics of financial industry clusters of Beijing using HI Index and EG Index, and we find that the two results are nearly the same, that the agglomeration level of industry is higher than other industries. After that, we discuss the factors affecting those, and put forward some hypotheses at the base of new economic geography. To test the hypotheses, we us factor analysis to extract common factors from the numerous indicators that may affect the financial industry gathering. The result shows that most variables are related with one factor, which we call it "modernization factor" on behalf of indicators representing the degree of modernization of Beijing's per capita income, level of information and economic system and one variable is related with the "human capital factor" representing Beijing's human capital. In order to get the relationship between the level of agglomeration of financial industry with the factors, we carry on a regression between them, showing a strong correlation. So we get the conclusion that the agglomeration of Beijing's financial industry is affected by the degree of informatization, external economics and the transaction costs.

\section{Acknowledgements}

This work was financially supported by Beijing Philosophy and Social Science Planning Research Project (13JDCSD002).

\section{References}

[1] Glaeser, E., Scheinkman, J.A. and Shleifer, A., "Economic growth in a cross-section of cities,"Journal of Monetary Economics 36, 117-143 (1995).

[2] Henderson, J.V., "The sizes and types of cities," American Economic Review 64, 640-656 (1974).

[3] Krugman, P., The Self-Organizaing Economy, Cambridge: Blackwell (1996).

[4] Fujita, M., "Location of firms with input transactions," Environmental and Planning A 13, 1401-1414(1981).

[5] Fujita, M. and Thisse, J.-F., Economics of Agglomeration, forthcoming, Cambridge: Cambridge University Press, Ch.2 (2001).

[6] Henderson, V., Urban Development, Oxford: Oxford University Press (1988).

[7] Krugman, P., The Self-Organizaing Economy, Cambridge: Blackwell (1996). 